\title{
Functional food availability, a limitation to peoples' health on Islands
}

\section{Rameshwar Sarma V. Kramadhati, Tuyetha Dinh, Judith Mekamkwe, Patrick Ndungu, and Erick Nguyen}

Saint James School of Medicine, Plaza Juliana 4, Kralendijk, Bonaire, Dutch Caribbean

Corresponding author: Rameshwar Sarma V. Kramadhati, Associate Professor, Saint James

School of Medicine, Plaza Juliana 4, Kralendijk, Bonaire, Dutch Caribbean

Submission date: April 21, 2011; Acceptance date: July 27, 2011; Publication date: July 30, 2011

\begin{abstract}
:
Background:

All foods are imported to markets in smaller islands in the Caribbean. Before export of foods to these destinations, the foods are subjected to several preservative procedures like irradiation, pesticide spray and prolonged refrigeration etc., to last the extended transport periods. This reduces availability of protective elements and the nutrient contents of the foods to scanty levels, especially to common people with low and middle incomes. Hence the majority of people in these categories on the small islands become vulnerable to ill health.
\end{abstract}

Aims and Objectives: To assess 1. Food availability 2. Normal transport period for foods to reach from the suppliers, and 3. Current level of prevalence of non-infective chronic diseases in the area.

Methods: Data were collected from two sources. One set of data was collected from the three supermarkets on the island to obtain information on source, transport time and nature of foods imported; and the second from 200 randomly selected responses of diseased persons for information on the age, gender and cause of death.

Results: All the foods were imported and the time taken for the food (including protective foods) to reach the island was about 3 weeks. The major causes of death were malignancy (30\%), diabetes and its complications (25\%), cardio vascular diseases (19.5\%), STD / HIV (8.5\%) and other causes (17.0\%). A review of prevalence of chronic diseases like hypertension, diabetes, heart diseases, arthritis and associated functional limitations, in the region reveals that their 
prevalence is proportionately high on the island compared to nearby developed mainland regions. Body mass index of $\geq 25$ was reported to be as high as $58.3 \%$. The health care facilities available are seen to be limited and public health activity to prevent or manage the prevailing chronic health issues, appeared to be meager.

Conclusion: There is a need to address the problem through public health actions to lower the incidence of the chronic degenerative diseases in the area: 1. Educate the community about the ways to improve their nutrition and life styles, 2. Make available health and nutrition promoting foods to all the people living in the islands, 3. Strengthen health services to tackle chronic degenerative diseases in the region.

Key Words: Foods, Nutrition, Chronic diseases, Mortality, Protective foods, Functional foods

\section{Background:}

All foods are imported to markets on smaller islands in the Caribbean, since food is not grown there due to poor soil conditions and whatever is grown is very limited. Before export to these destinations, the foods are subjected to several preservative processes like irradiation, heavy pesticide spray and prolonged refrigeration etc., to last the extended transport periods. This reduces availability of protective elements and the nutrient contents of the foods, especially protective and functional foods, to low levels. The limited availability and the cost further restrict the desirable nutrient availability, especially to common people with low and middle incomes. Hence the majority of people in these categories in the small islands become vulnerable to ill health and its consequences.

To understand the concept comprehensively, the demography and climate of the region need to be understood well. The demographic characteristics ${ }^{1}$ are explained in Figure-1.

Fig. 1: Age categories in the Dutch Caribbean population 


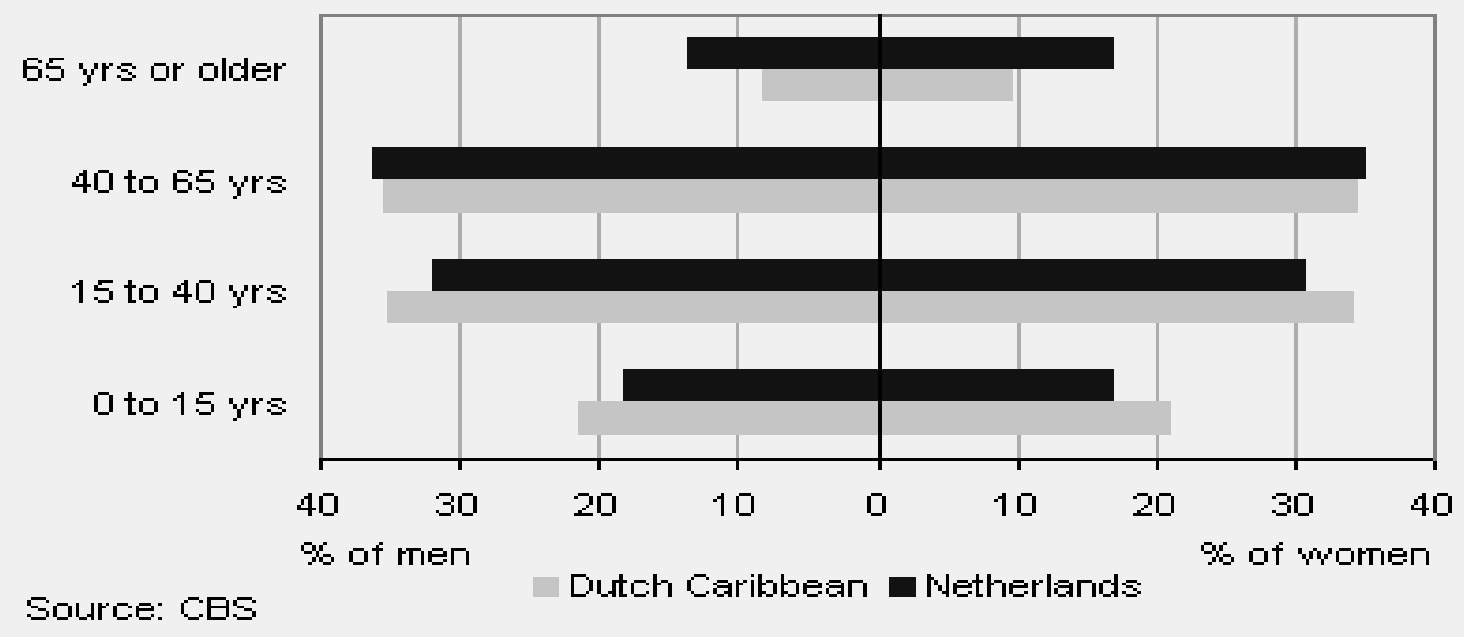

Since 10 October 2010, the Caribbean islands of Bonaire, Saba, Sint Maarten and Sint Eustatius have officially acquired the status of Dutch municipalities. The population of Bonaire is 13, 389 as on $1^{\text {st }}$ January 2010. The average age of the residents in Bonaire is 35.7 years and this is 4.4 years younger than people living in the Netherlands. The most substantial difference is recorded in the proportion of older people in both populations: less than 9 percent of the Dutch Caribbean population is 65 years of age or older as against more than 17 percent of the Dutch population in Europe. The marginally higher number of Dutch Caribbean children and the significantly lower life expectancy of Dutch Caribbean men partly account for the difference.

Young adults are relatively rare on the islands of Bonaire and Saint Eustatius. This is probably due to many young people having moved to the Netherlands to work or study. Over the past five years, immigrants outnumbered emigrants on Bonaire.

\section{Socio-economic status:}

Most of the residents belong to the Roman Catholic Church (73\%). Lower secondary education is the highest level of education for the majority (43\%), while $23 \%$ had primary level education and $13 \%$ had completed higher vocational or academic education. The rest had minimal ( $<3 \mathrm{yr})$ schooling or no formal education. Women have a lower level of education. Household income of $33 \%$ is less than US \$ 825, while 38\% have income between US \$ 825 and 1650 and $29 \%$ earn more than US \$ 1650 per month.

\section{Area and Climate}

The islands previously comprising the Netherlands Antilles enjoy a mild tropical climate, fairly constant throughout the year ${ }^{2}$. However, the climate of the semi-arid Leeward Islands - Bonaire and Curaçao - shows significant difference when compared with the lush, greenery Windward Islands of Saba, Sint Eustatius and Sint Maarten, which are located within the Atlantic hurricane belt. 
Aims and Objectives: The aims of the present study were to assess: 1. Sources of foods and food practices; 2. Normal transport period for foods to reach from the suppliers to the island and, 3. Prevalence of non-infective chronic diseases in the area.

\section{Methods:}

Data were collected from two sources for the purpose of this study. One set of data was obtained from the three supermarkets on the island, in order to obtain information on source, transport time and nature of foods imported. A second set of data was collected using two types of questionnaire that were canvassed to obtain: (i) Information on the supply and nature of foods in Bonaire and (ii) Information on the most frequent causes leading to death on the island. The first questionnaire was designed to obtain information from three of Bonaire's supermarkets, to determine how long it takes for food to leave the distributors and reach consumers. The second one was canvassed to collect particulars from 200 randomly selected relatives or close acquaintances of deceased individuals on the island, to derive information on causes of death. To ensure reliable information on the nature and quality of foods from the three Bonaire supermarkets, it was ensured that the results were kept strictly confidential and anonymous.

\section{Results:}

Summarization and analysis of the collected data indicated that most of the food on Bonaire was imported from Miami, followed by Holland, Curacao and Venezuela. It took on average three weeks for food products to leave the suppliers and reach consumers. Consumers visit the stores on the day foods arrive on the island and many find that they are already late and have to wait for their choice of food items till the next delivery.

The practice of reducing prices was observed when fresh foods started deteriorating and it was not uncommon to see such food products sometimes on sale on the racks.

Protective and functional food eating habits were assessed by canvassing via a food frequency questionnaire to obtain information on consumption, including frequency of intake. Consumption frequencies, when analyzed according to following categories: (i) daily consumption, (ii) consumption of 3-5 times a week, (iii) consumption of two or less times a week and (iv) never consumed; revealed that only about half $(56 \%)$ of Bonaireans consumed vegetables and milk/milk products daily and fruits were consumed only by less than half (46\%). About five and seven percent of them mentioned that they never consumed any vegetables or fruits/milk/milk products in a week, respectively.

Table 1: Habits of Protective Food Consumption

\begin{tabular}{|l|l|l|l|l|}
\hline \multirow{2}{*}{ Items } & \multicolumn{4}{|c|}{ Times per week } \\
\cline { 2 - 5 } & Daily & $3-5$ & $1-2$ & Never \\
\hline
\end{tabular}




\begin{tabular}{|l|l|l|l|l|}
\hline Vegetables & $56 \%$ & $24 \%$ & $15 \%$ & $4 \%$ \\
\hline Fruits & $46 \%$ & $21 \%$ & $25 \%$ & $7 \%$ \\
\hline Milk and products & $56 \%$ & $21 \%$ & $16 \%$ & $7 \%$ \\
\hline
\end{tabular}

About twenty percent stated that health promoting foods were consumed only 3 to 5 times a week and a similar proportion even less frequently i.e. 1 to 2 times a week. Consumption of functional foods like probiotics, prebiotics, turmeric (curcumin), ginger and other spices was very meager.

Data on cause of death (Table-2) indicate that chronic disorders like cardiovascular diseases, diabetes and its complications, and malignancy were the major killers with cardio vascular diseases taking the major toll, even in comparatively young people.

Table-2: Age and cause of death

\begin{tabular}{|l|l|l|}
\hline Age at death & Cause of death & \% deaths \\
\hline $35-70$ & cardio vascular & 19.5 \\
\hline $57-80$ & diabetes and complications & 25.0 \\
\hline $33-75$ & malignancy & 30.0 \\
\hline children and young adults & accidents & 3.0 \\
\hline $27-47$ & & \\
\hline$>90$ & Std incl. HIV & 8.5 \\
\hline different ages & natural causes & 0.5 \\
\hline & other causes & 13.5 \\
\hline
\end{tabular}

\section{Discussion:}

All the foods were imported and the time taken for all the food to reach the island was on average at least three weeks. The availability of foods, especially fresh vegetables, fruits and functional foods was limited, leading to reduced consumption of protective and health promoting foods.

Evidence is accumulating ${ }^{3-16}$ on the protective role of functional foods like turmeric, and functional foods like probiotics and prebiotics in the prevention of cancers, heart diseases, diabetes and cataracts. Hence the limited availability of health promoting foods poses a challenge to people living on the island.

A review of prevalence of chronic diseases (Table 3) like hypertension, diabetes, heart diseases, arthritis and associated functional limitations in the region ${ }^{17}$ reveals that their prevalence is proportionately high compared to people living on the mainland. There are gender 
variations in the prevalence of hypertension, diabetes and chronic obstructive pulmonary disorders, and the prevalence of heart diseases is three times higher in women. The prevalence also increased, as expected, with advancing age, clearly indicating influence of diet, nutrition and physical activity. The level of physical activity was significantly lower in females. Consumption of alcohol (78\% vs 55\%) and smoking (31\% vs 10\%) was considerably higher in males compared to females, with number of cigarettes smoked per day reaching 10 .

Body mass index (BMI) $\geq 25$ was reported $^{17}$ to be at $58.3 \%$. Compared to Netherlands (39.6\%) the proportion with $\geq 25$ BMI was very high, more so in women $(61.6 \%)$ as seen in Figure 2.

The health care facilities available were limited and public health activity, to prevent or manage the prevailing chronic health issues, appeared to be inadequate. Bonaire has since become a special municipality of Netherlands, it is expected that the situation will improve in the course of time.

Table 3: Percent Prevalence of some chronic diseases in one year in Bonaire

\begin{tabular}{|l|c|c|c|c|c|c|c|}
\hline \multirow{2}{*}{ disorders } & \multirow{2}{*}{ total } & \multicolumn{2}{|c|}{ gender } & \multicolumn{4}{|c|}{ age (years) } \\
\cline { 3 - 8 } & & $\mathrm{m}$ & $\mathrm{f}$ & $18-24$ & $25-44$ & $45-64$ & $\geq 65$ \\
\hline HYPERTENSION & 14.4 & 9.4 & 19.2 & 1.9 & 8.0 & 24.0 & 27.3 \\
\hline DIABETES MELLITUS & 6,7 & 3.9 & 9.4 & 0.0 & 3.3 & 10.5 & 17.3 \\
\hline COPD & 3.4 & 2.4 & 4.3 & 3.1 & 3.9 & 3.9 & 2.7 \\
\hline HEART DISEASE & 2.8 & 1.8 & 3.7 & 1.9 & 0.8 & 3.6 & 10.0 \\
\hline CANCER & 0.4 & 0.4 & 0.4 & 0.0 & 0.2 & 0.7 & 0.9 \\
\hline $\begin{array}{l}\text { OTHER CHRONIC } \\
\text { DISORDERS }\end{array}$ & 4.2 & 4.1 & 4.3 & 3.9 & 5.2 & 2.6 & 4.5 \\
\hline
\end{tabular}

Fig. 2: Prevalence of overweight $(\mathrm{BMI}>25)$ 


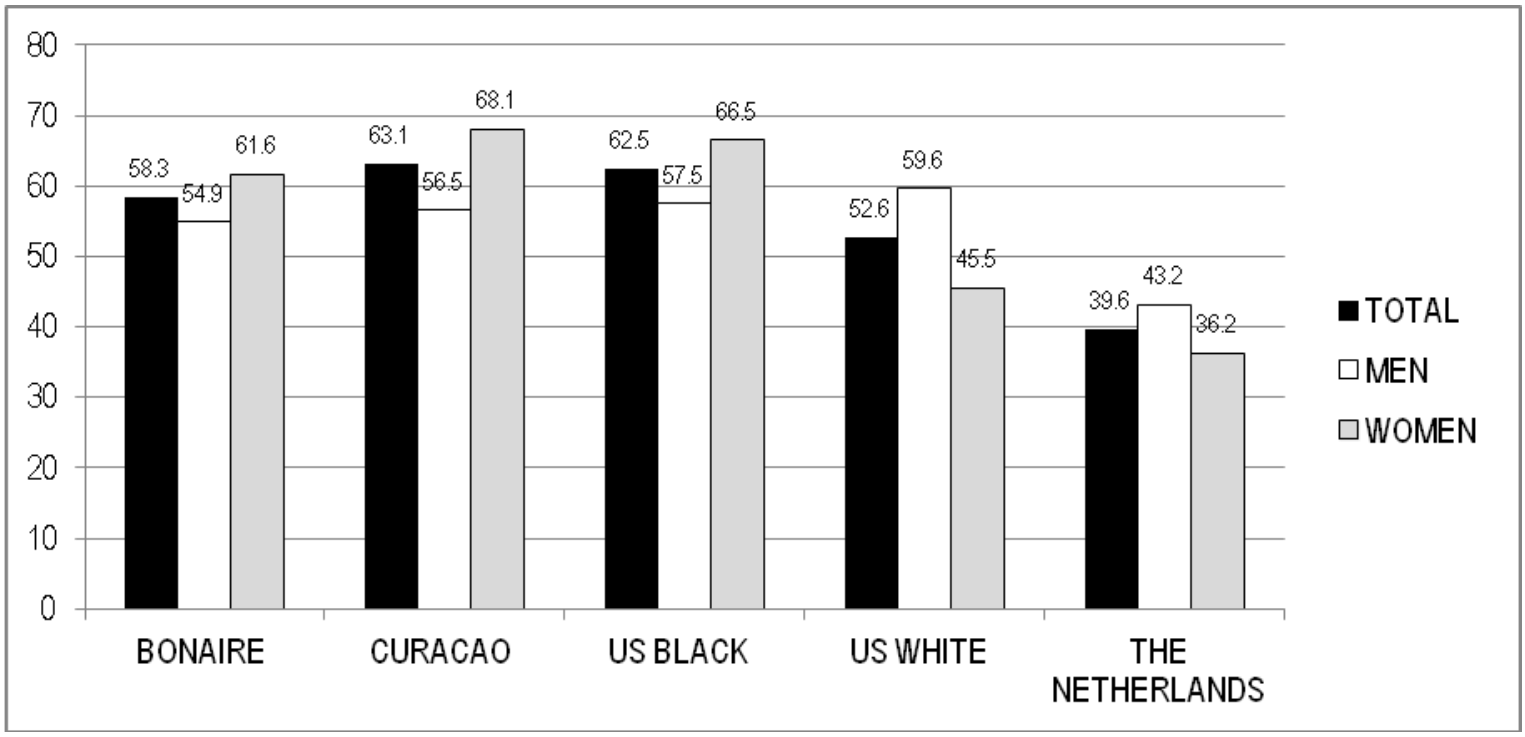

In addition to the disadvantage of irradiation ${ }^{18-21}$ much of the imported foods are known to contain twice the amount of pesticide residues ${ }^{22,23}$ than locally grown produce. Regardless of the benefits of pesticides in protecting foods from microbes, there also come disadvantages, like increased cancer risks. Indeed, most chemicals are toxic when applied at high enough levels, and imported fruits and vegetables remain a major pesticide dietary risk concern. In the United States, the Environmental Protection Agency (EPA) has proposed the Dietary Risk Index (DRI) to measure amounts of pesticide residues in fruits and vegetables. DRI measures the average risks stemming from pesticide residues in a typical serving of food. The equation appears as follows: DRI $=($ Percent Positive $) \times($ Chronic Risk Share), where "Percent positive" measures how frequently a pesticide residue is found on a fruit or vegetable, and "chronic risk share" measures the level of risk associated with the residues of a pesticide found on produce. Along with irradiation and pesticides, another disadvantage is that frozen meat imports lack nutritive value and contain more harmful elements that may cause diseases. In some countries, such as Vietnam, imported frozen meat must be distributed through several official channels and only reaches the customers after several months, sometimes a year. The Vietnam Association of Food Science and Technology says ${ }^{24}$ an extensive period of freezing will transform some kinds of nutritious proteins into toxins. Extensive periods of freezing are likely to make food more prone to bacterial and viral invasions. Imported foods may contain fewer vitamins, minerals, and more pesticides. In addition, after being kept frozen for too long, only $30 \%$ of its content is nutritious and the rest is toxic. Meat is usually frozen at 20 degrees Celsius below zero to keep it from rotting. Even if the low temperatures can guarantee that the meat is fine, it will lose many vitamins and minerals, such as zinc and magnesium and polyunsaturated fatty acids. Furthermore, the changes in temperature of meat with multiple freezing episodes create ideal conditions for bacteria to reproduce. According to research done in Saudi Arabia in 2006, the frequency of isolation of different bacterial strains from imported frozen chicken meat was 
higher than that of local frozen chicken meat ${ }^{25}$. Some of these bacteria include Enterobacteriaceae, Staphylococcus aureus, and Lactobacillacea.

\section{Conclusion:}

The lifespan of an average Bonairean seems to be influenced by the lack of adequate quantity and quality of health promoting foods available on the island. Though environmental factors pose a low risk in Bonaire as Bonaire homes no factories, the air in Bonaire is not polluted as the name itself specifies (Bonaire=Clean air) in contrast to many developed and developing countries, the health of the Bonairean people seem to be greatly affected by the life style factors, diet and habits.

There is a need to address the problem through public health actions to lower the incidence of the chronic degenerative diseases in the area viz: 1. Educate the community about ways to improve their nutrition and life styles; 2 . Make available health and nutrition promoting foods to all the people living on the island; 3. Strengthen health services to tackle chronic degenerative diseases in the region.

\section{Recommendations:}

Efforts are needed to encourage residents to grow vegetables and fruits in order to produce protective and health promoting foods at lower costs. Till such time the residents need to be advised to shop as often as possible to avoid refrigerating foods from supermarkets for too long, which can result in growth of microorganisms. Consumers should include more fruits and raw vegetables, unless cooking is absolutely necessary, as cooked green-leafed vegetables have greatly reduced amounts of vitamins and minerals. Parents, especially if both parents are employed, need to ensure that their children also inculcate this habit and avoid junk foods and aerated drinks. Lastly, it is desirable that Bonaire supermarkets strive to reduce the food transport time and have better cooling systems, as well as to stock products according to manufacturers and producers regulations regarding appropriate storage conditions of food items.

\section{Competing interests:}

This study was not sponsored by any funding agency. The authors have no conflicts of interest in any of the information presented in this manuscript.

\section{Author's contribution:}

The article by the authors is based on the research work done at Saint James School of Medicine, Bonaire, Dutch Caribbean and a presentation with the title FUNCTIONAL FOOD AVAILABILTY, A LIMITATION TO PEOPLES' HEALTH IN ISLANDS" given at the 8th International Conference; Functional Foods for Chronic Diseases: Science and Practice; March 15-17, 2011, University of Nevada, Las Vegas, USA by Dr Rameshwar Sarma, Dr Rameshwar Sarma has designed, 
supervised conduction of the study and written the article while the rest of the authors have contributed by collection of the data from supermarkets and community.

\section{Abbreviations:}

The abbreviations used in the article are explained in the text itself.

\section{Acknowledgements:}

First and foremost, the authors would like to thank Saint James School of Medicine for giving the opportunity to partake in this research experience and learn more about the island of Bonaire. The authors also thank the Bonaire supermarkets for allowing the conduct of the study. They also thank Dr Bruce Davidson, Professor and Dean, Saint James School of Medicine, Bonaire for editing the article. Last but not least, thanks to the Bonaire people for their time and patience during the interviews.

\section{References:}

1. Central Bureau of Statistics. Netherlands Antilles 2010.

2. Source: Meteorological Service, Netherlands Antilles and Aruba 2008

3. Cheng AL, Hsu CH, Lin JK, et al. Phase I clinical trial of curcumin, a chemopreventive agent, in patients with high-risk or pre- malignant lesions. Anticancer Res. 2001; 21: 28952900.

4. Deeb D, Jiang H, Gao X, et al. Curcumin sensitizes prostate cancer cells to tumor necrosis factor-related apoptosis-inducing ligand/Apo2L by inhibiting nuclear factor- $\kappa \mathrm{B}$ through suppression of I\&945; phosphorylation. Mol Cancer Ther. 2004; 3: 803-812.

5. Elattar TMA, Virji AS. The inhibitory effect of curcumin, genistein, quercetin and cisplatin on the growth of oral cancer cells in vitrol. Anticancer Res. 2000; 20:1733-1738.

6. Bharti AC, Shishodia S, Reuben JM, et al. Nuclear factor- $\kappa$ B and STAT3 are constitutively active in $\mathrm{CD} 138^{\wedge}$ sup $+^{\wedge}$ cells derived from myeloma patients and suppression of these transcription factors leads to apoptosis. Blood. 2004; 103: 3175-3184.

7. Radhakrishna Pillai G, Srivastava AS, Hassanein TI, Chauhan DP, Carrier E. Induction of apoptosis in human lung cancer cells by curcumin. Cancer Lett. 2004; 208: 163-170.

8. Shao Z-M, Shen Z-Z, Liu C-H, et al. Curcumin exerts multiple suppressive effects on human breast carcinoma cells. Int J Cancer. 2002; 98:234-240.

9. Arun N, Nalini N. Efficacy of turmeric on blood sugar and polyol pathway in diabetic albino rats. Plant Foods Hum Nutr. 2002; 57:41-52

10. Akhilender Naidu K, Thippeswamy NB. Inhibition of human low density lipoprotein oxidation by active principles from spices. Mol Cell Biochem. 2002; 229: 19-23.

11. Lasheras C, Huerta JM, Gonzalez S, et al. Diet store is associated with plasma homocysteine in healthy institutionalised elderly population. Nutr Metab Cardiovasc Dis. 2003; 13:384390. 
12. Tucker KL, Selhub J, Wilson PWF, Rosenberg IH. Dietary intake pattern relates to plasma folate and homocysteine concentrations in the Framingham Heart Study. J Nutr. 1996; 126: 3025-3031.

13. Bengmark, Stig. Curcumin, an Atoxic Antioxidant and Natural NF [Kappa] B, Cyclooxygenase-2, Lipooxygenase, and Inducible Nitric Oxide Synthase Inhibitor: A Shield Against Acute and Chronic Diseases. VISION, 2003; 9: 223- 230.

14. Palla Suryanarayana, Kamala Krishnaswamy, Geereddy Bhanuprakash Reddy. Effect of curcumin on galactose-induced cataractogenesis in rats. Molecular Vision 2003; 9: 223-230

15. Kamala Krishnaswamy, Kalpagam Polasa: Nonnutrients and Cancerprevention. Icmr Bull. 31 (1):1-9, 2001.

16. Polasa, K; Naidu, AN; Ravindranath, I; Kamala Krishnaswamy, Inhibition of b(a)p Induced Strand Breaks in Presence of Curcumin. Mutation Research, 2003.

17. Grievink, L. Fuchs, G. O’Niel, J. van Sonderen, E. Gerstenbluth, I. and Alberts, J.F. "The Bonaire Health Study" ISOG Curacao, 2002. Curacao, Netherlands Antilles, The Foundation for Promotion of International cooperation and Research; 2002.

18. CNCA. "The Pros and Cons of Food Irradiation." Livestrong Challenge Austin. 12 November 2009 < http://blog.cncahealth.com/post/2009/11/12/The-Pros-and-Cons-of-FoodIrradiation.aspx $>$.

19. “What's Wrong With Food Irradiation?” Organic Consumers Association. February 2001 http://www.organicconsumers.org/irrad/irradfact.cfm>.

20. Congressional Committees. "Food Irradiation: FDA Could Improve Its Documentation and Communication of Key Decisions on Food Irradiation Petitions." United States Government Accountability Office. February 16, 2010.

21. "Food Irradiation." FMI Backgrounder. 2010 <www.fmi.org/media/bg/foodirradiation.pdf>.

22. "Pesticides in the Food Supply." Food Marketing Institute. 2010 <www.fmi.org/docs/media/bg/pests.pdf>.

23. Benbrook, Charles. "Simplifying the Pesticide Risk Equation: the Organic Option." March 2008. State of Science Review: the Organic Center.

24. Quang, Thuan. "Imported frozen meat not good for health, Experts Say." Look at Vietnam. May 5, 2009 <http://www.lookatvietnam.com/2009/05/imported-frozen-meat-not-good-forhealth-experts-say.html>.

25. Altalhi, A. Sultan Qabos University. "Bacteriological study of frozen meat in Taif Governorate in Saudi Arabia." April 2006 <http://www.citizen.org/cmep/foodsafety/international/articles.cfm?ID=7675>

26. Tuyetha Dinh, Judith Mekamkwe, Patrick Ndungu, Erick Nguyen "Imported Foods and their Effect on the Health of People in Bonaire" SJSM April, 2010 (Unpublished Report) 